TENDENCIAS

Revista de la Facultad de Ciencias

Económicas y Administrativas.

Universidad de Nariño

ISSN-E 2539-0554

Vol. XXIII No. 1 - 1er Semestre 2022

Enero - Junio - Páginas 277-314

\title{
CONDICIONES OCUPACIONALES DE LOS GRADUADOS DEL PROGRAMA DE ECONOMÍA EN LA UNIVERSIDAD DE NARIÑO, COLOMBIA
}

\section{OCCUPATIONAL CONDITIONS OF ECONOMY PROGRAM ALUMNI OF THE UNIVERSITY OF NARIÑO, COLOMBIA}

\author{
CONDIÇÕES OCUPACIONAIS DOS GRADUADOS DO PROGRAMA DE \\ ECONOMIADA DA UNIVERSIDADE DE NARIÑO, COLÔMBIA
}

\author{
Mario Eduardo Hidalgo Villota
}

\begin{abstract}
Magíster en Políticas Públicas, Universidad del Valle, Colombia. Profesor Asistente Departamento de Economía, Universidad de Nariño, Colombia. Grupo de Investigación en Economía, Gobierno y Políticas Públicas de la Universidad de Nariño. ORCiD: 0000-0002-5579-6136. E-mail: mariohidalgo@udenar.edu.co,Colombia.
\end{abstract}

Recibido: 12 de agosto de 2021

Aprobado: 5 de octubre de 2021

DOI: https://doi.org/10.22267/rtend.222301.191

\section{Resumen}

En este artículo se analizan las condiciones ocupacionales y el desempeño profesional de los economistas de la Universidad de Nariño, Colombia, en concordancia con la política universitaria de autoevaluación y mejora permanente de la calidad académica. Este es un estudio con enfoque mixto de tipo observacional, prospectivo, transversal y descriptivo, el cual incorpora en su análisis, información primaria recolectada a través de encuestas y entrevistas contestadas por un número representativo de graduados en el periodo 1979-I - 2020-II. El uso de métodos estadísticos y 
econométricos, así como el análisis riguroso de datos cualitativos, permite confirmar el éxito profesional de los economistas en su inserción laboral, el reducido tiempo de búsqueda en la consecución del primer empleo, la moderada tasa de desempleo, los avances en formación posgradual y la no discriminación laboral; a esto, se suma, el equilibrio salarial de género y la equitativa distribución del ingreso entre mujeres y hombres.

Palabras clave: condiciones de trabajo; discriminación sexual; economía del trabajo; mercado de trabajo; profesión.

JEL: J01, J15, J16, J31, J71, J81

\begin{abstract}
This article analyzes the occupational conditions and professional performance of economists from the University of Nariño, Colombia in accordance with the university policy of self-evaluation and permanent improvement of academic quality. This study employs a mixed observational prospective, cross-sectional and descriptive approach, which considers primary information collected through surveys and interviews with a representative number of alumni who graduated between 1979-I and 2020-II. The use of statistical and econometric methods, as well as the rigorous analysis of qualitative data, demonstrate the professional success of economists in their labor insertion, reduced search period before obtaining their first job, a moderate unemployment rate, the advances in postgraduate training and non-discrimination in employment. In addition, the research shows gender wage balance and the equitable distribution of income between women and men.
\end{abstract}

Keywords: working conditions; sexual discrimination; labor economics; labor market; profession. JEL: J01, J15, J16, J31, J71, J81

\title{
Resumo
}

Este artigo analisa as condições ocupacionais e o desempenho profissional dos economistas da Universidade de Nariño, Colômbia; de acordo com a política universitária de autoavaliação e melhoria permanente da qualidade acadêmica. Trata-se de um estudo de abordagem mista observacional, prospectiva, transversal e descritiva, que incorpora em sua análise informações 
primárias coletadas por meio de pesquisas e entrevistas respondidas por um número representativo de egressos no período 1979 - I a 2020 - II. A utilização de métodos estatísticos e econométricos, bem como a análise rigorosa de dados qualitativos, permitem constatar o sucesso profissional dos economistas na sua inserção laboral, o reduzido tempo de procura na obtenção do primeiro emprego, a moderada taxa de desemprego, os avanços em formação pós-graduada e não discriminação no emprego; soma-se a isso o equilíbrio salarial por gênero e a distribuição equitativa da renda entre mulheres e homens.

Palavras-chave: condições de trabalho; discriminação sexual; economia do trabalho; mercado de trabalho; profissão.

JEL: J01, J15, J16, J31, J71, J81

\section{Introducción}

El seguimiento de egresados es un asunto de vital importancia para las universidades, ya que el desempeño profesional y personal de los egresados permite establecer indicadores con respecto a la calidad y eficiencia de las instituciones de educación superior (Red Gradua2 \& Asociación Columbus, 2006, pág. 5). En esa misma línea, el Centro para la Investigación sobre la Educación Superior y el Trabajo de la Universidad de Kassel, Alemania (2004), como referente mundial en investigación científica, señala que los estudios de graduados (y de empleadores) proveen información valiosa para evaluar los resultados de la educación superior y de la calidad académica de los programas universitarios en un contexto de mejoramiento continuo.

Si bien los estudios de seguimiento a egresados pueden abordar diferentes tópicos que den cuenta del aporte de los programas en el medio académico y social, la presente investigación se centró en las condiciones ocupacionales de los graduados del Programa de Economía en el periodo 1979-I - 2020-II, aportando evidencia empírica y testimonios de la contribución del programa al desarrollo de habilidades profesionales, ocupacionales y personales de los economistas formados integralmente en la Universidad de Nariño.

Las condiciones laborales determinan en alto grado el éxito profesional, razón por la cual, en esta investigación se consideraron variables y factores analíticos discriminados por sexo que indagan 
sobre las condiciones del sitio de trabajo (higiene, ventilación, iluminación, ruido, vibraciones, radiación excesiva, luz solar, humo, sustancias tóxicas, áreas húmedas, espacios físicos reducidos, etc.), los ingresos laborales, la formación posgradual, las dimensiones y criterios ligados a la conceptualización del trabajo decente y su medición, el tiempo de búsqueda del primer empleo, la tasa de desempleo, el nivel de satisfacción de los economistas con respecto a los salarios recibidos y la ocupación actual, la discriminación económica, la concentración del ingreso, entre otras.

\section{Un breve recorrido por la historia del Programa de Economía.}

Mediante el Acuerdo Número 018 del 22 de junio de 1973 se creó la Facultad de Economía (FAECO) de la Universidad de Nariño, cuyos objetivos se resumen en: a) servir de núcleo principal para el desarrollo del programa de economía y el Departamento de Investigaciones Económicas; b) organizar y llevar adelante los programas de investigación en el campo de las ciencias económicas; c) encargarse en la enseñanza de la economía en las diferentes facultades de la Universidad, de acuerdo con los planes de estudios de las respectivas carreras; y d) colaborar en la planificación y programación económica de la Universidad. Los considerandos 2 y 3 del citado acuerdo, especifican que la creación del programa de economía es una respuesta a la legítima aspiración de los nuevos bachilleres y que le corresponde a la Facultad de Economía formar profesionales enfocados al estudio y resolución de problemas socioeconómicos a nivel local, regional y nacional. Al analizar el contenido del acuerdo arriba citado, se concluye que el programa de economía fue creado para promover el desarrollo económico y social del Departamento de Nariño con un gran liderazgo en el apoyo a la gestión de la Universidad de Nariño.

El Instituto Colombiano de Fomento de Educación Superior (ICFES) mediante Acuerdo Número 286 del 14 de noviembre de 1975, le concedió al Programa de Economía la licencia para iniciar labores académicas en la sede Pasto. A través del Acuerdo Número 089 de 11 de junio de 1976, se concede la licencia de funcionamiento, resaltando que el Programa de Economía cuenta con una estructura administrativa sólida y una calidad académica satisfactoria. Así mismo, el Consejo Superior de la Universidad de Nariño mediante Acuerdo Número 111 del 28 de julio de 1992 creó el Programa de Administración de Empresas y a través del Acuerdo Número 110 del 28 de julio de 1992, se modificó el nombre de la Facultad de Economía (FAECO) por Facultad de Ciencias Económicas y Administrativas (FACEA). De igual manera, en 1993 se creó el Programa de 
Comercio Internacional, en 2010 nace el Programa de Contaduría Pública y en 2011 se creó el Programa de Mercadeo.

La formación de economistas en la Universidad de Nariño ha sido un proceso bastante dinámico. A 9 de febrero de 2021 se registran 1.824 graduados, con un crecimiento singular de la tasa de graduación en la última década del siglo XX y primera década del siglo XXI. En el periodo 1979I a 1989-II la tasa de graduación es de 1,75\%, 6,79\% para el periodo comprendido entre 1990-I y 1999-II, 3,56\% para el periodo de 2000-I a 2009-II y una tasa de decrecimiento de -0,029\% para el periodo comprendido entre 2010-I y 2020-II. La tasa de crecimiento de los graduados en el periodo 1979-I y 2020-II es de 1,87\% (véase Tabla 1). 


\section{Tabla 1}

Graduados en el Programa de Economía 1979-I - 2020-II

\begin{tabular}{|c|c|c|c|c|c|c|c|c|c|c|c|c|c|c|c|}
\hline Año & Sem. & $\begin{array}{c}\text { Frec. } \\
\text { abs. }\end{array}$ & $\begin{array}{c}\text { Frec. } \\
\text { rel. }(\%)\end{array}$ & Año & Sem. & $\begin{array}{c}\text { Frec. } \\
\text { abs. }\end{array}$ & $\begin{array}{c}\text { Frec. } \\
\text { rel. }(\%)\end{array}$ & Año & Sem. & $\begin{array}{c}\text { Frec. } \\
\text { abs. }\end{array}$ & $\begin{array}{c}\text { Frec. } \\
\text { rel. }(\%)\end{array}$ & Año & Sem. & $\begin{array}{c}\text { Frec. } \\
\text { abs. }\end{array}$ & $\begin{array}{c}\text { Frec. } \\
\text { rel. }(\%)\end{array}$ \\
\hline \multirow{2}{*}{1979} & $\mathrm{~A}$ & 10 & 0,55 & \multirow{2}{*}{1990} & $\mathrm{~A}$ & 14 & 0,77 & \multirow{2}{*}{2001} & $\mathrm{~A}$ & 4 & 0,22 & \multirow{2}{*}{2011} & $\mathrm{~A}$ & 32 & 1,75 \\
\hline & B & 0 & 0,00 & & $\mathrm{~B}$ & 9 & 0,49 & & B & 25 & 1,37 & & B & 21 & 1,15 \\
\hline \multirow{2}{*}{1980} & A & 9 & 0,49 & \multirow{2}{*}{1991} & A & 13 & 0,71 & \multirow{2}{*}{2002} & A & 19 & 1,04 & \multirow{2}{*}{2012} & A & 27 & 1,48 \\
\hline & B & 11 & 0,60 & & B & 5 & 0,27 & & B & 17 & 0,93 & & B & 19 & 1,04 \\
\hline \multirow{2}{*}{1981} & $\mathrm{~A}$ & 5 & 0,27 & \multirow{2}{*}{1992} & $\mathrm{~A}$ & 12 & 0,66 & \multirow{2}{*}{2003} & $\mathrm{~A}$ & 14 & 0,77 & \multirow{2}{*}{2013} & $\mathrm{~A}$ & 34 & 1,86 \\
\hline & $\mathrm{B}$ & 2 & 0,11 & & B & 32 & 1,75 & & B & 14 & 0,77 & & B & 26 & 1,43 \\
\hline \multirow{2}{*}{1982} & A & 15 & 0,82 & \multirow{2}{*}{1993} & A & 24 & 1,32 & \multirow{2}{*}{2004} & A & 36 & 1,97 & \multirow{2}{*}{2014} & A & 36 & 1,97 \\
\hline & $\mathrm{B}$ & 5 & 0,27 & & $\mathrm{~B}$ & 59 & 3,23 & & $\mathrm{~B}$ & 30 & 1,64 & & $\mathrm{~B}$ & 47 & 2,58 \\
\hline \multirow{2}{*}{1983} & $\mathrm{~A}$ & 3 & 0,16 & \multirow{2}{*}{1994} & $\mathrm{~A}$ & 22 & 1,21 & \multirow{2}{*}{2005} & $\mathrm{~A}$ & 27 & 1,48 & \multirow{2}{*}{2015} & $\mathrm{~A}$ & 16 & 0,88 \\
\hline & $\mathrm{B}$ & 8 & 0,44 & & $\mathrm{~B}$ & 65 & 3,56 & & $\mathrm{~B}$ & 24 & 1,32 & & $\mathrm{~B}$ & 28 & 1,54 \\
\hline \multirow{2}{*}{1984} & A & 6 & 0,33 & \multirow{2}{*}{1995} & A & 21 & 1,15 & \multirow{2}{*}{2006} & A & 4 & 0,22 & \multirow{2}{*}{2016} & A & 28 & 1,54 \\
\hline & $\mathrm{B}$ & 9 & 0,49 & & $\mathrm{~B}$ & 29 & 1,59 & & $\mathrm{~B}$ & 27 & 1,48 & & $\mathrm{~B}$ & 32 & 1,75 \\
\hline \multirow{2}{*}{1985} & $\mathrm{~A}$ & 1 & 0,05 & \multirow{2}{*}{1996} & $\mathrm{~A}$ & 25 & 1,37 & \multirow{2}{*}{2007} & $\mathrm{~A}$ & 20 & 1,10 & \multirow{2}{*}{2017} & $\mathrm{~A}$ & 17 & 0,93 \\
\hline & B & 3 & 0,16 & & B & 50 & 2,74 & & B & 28 & 1,54 & & B & 26 & 1,43 \\
\hline \multirow{2}{*}{1986} & $\mathrm{~A}$ & 21 & 1,15 & & $\mathrm{~A}$ & 24 & 1,32 & & $\mathrm{~A}$ & 56 & 3,07 & & $\mathrm{~A}$ & 15 & 0,82 \\
\hline & $\mathrm{B}$ & 27 & 1,48 & 1997 & $\mathrm{~B}$ & 82 & 4,50 & 2008 & $\mathrm{~B}$ & 22 & 1,21 & 2018 & B & 13 & 0,71 \\
\hline 1987 & $\mathrm{~A}$ & 3 & 0,16 & 1998 & A & 56 & 3,07 & 2009 & $\mathrm{~A}$ & 25 & 1,37 & 2019 & A & 8 & 0,44 \\
\hline 1981 & B & 10 & 0,55 & 1998 & B & 45 & 2,47 & 2009 & B & 32 & 1,75 & 2019 & B & 34 & 1,86 \\
\hline & A & 2 & 0,11 & 190 & A & 27 & 1,48 & & A & 11 & 0,60 & & A & 15 & 0,82 \\
\hline 1988 & $\mathrm{~B}$ & 10 & 0,55 & 1999 & $\mathrm{~B}$ & 16 & 0,88 & 2010 & $\mathrm{~B}$ & 36 & 1,97 & 2020 & $\mathrm{~B}$ & 10 & 0,55 \\
\hline 1989 & $\mathrm{~A}$ & 6 & 0,33 & 2000 & $\mathrm{~A}$ & 25 & 1,37 & & & & & & & & \\
\hline 1909 & $\mathrm{~B}$ & 9 & 0,49 & 2000 & B & 20 & 1,10 & & & & & & & & \\
\hline & & 175 & 9,6 & & & 675 & 37,0 & & & 471 & 25,8 & & & 484 & 26,5 \\
\hline & & & & & Total C & raduad & & & & & & & & 1.824 & 100,0 \\
\hline
\end{tabular}

Fuente: Elaboración propia a partir de la revisión del archivo histórico y bases de datos Centro Informática. 


\section{El trabajo y el empleo: una breve reflexión teórica}

Neffa (1999, págs. 2-3) señala que el trabajo en la antigüedad era considerado como una actividad física penosa, que moviliza un saber productivo, utiliza herramientas apropiadas y se sirve de una tecnología; mediante un conjunto coherente de operaciones técnicas produce los medios materiales para garantizar la existencia humana. El autor prosigue afirmando que, el trabajo en la antigüedad no necesariamente tenía como fin una remuneración en dinero o en especie; este formaba parte de ciertas obligaciones sociales al interior de la familia o un grupo social; es decir, el trabajo siendo una actividad individual se realizaba en un contexto social con un propósito supraindividual. De La Garza (2000) también coincide en que el sentido del trabajo ha cambiado en el mundo; en la economía de la antigüedad, este era considerado una tortura o una desgracia, razón por la cual, era asignado a los esclavos; los nobles, en cambio, se dedicaban a la gestión política, a la disertación filosófica y al ocio.

En los anteriores pasajes se observa que el concepto del trabajo humano ha sufrido transformaciones a través de la historia. En el estadio medieval fue comparado con el "yugo" como instrumento de tortura. Neffa (1999) señala que, a partir de la reforma protestante y del pensamiento de Calvino y Lutero, el trabajo adquiere una dimensión ética que permite justificar el beneficio económico obtenido por este. Neffa también afirma que Hegel consideraba que el trabajo tenía una dimensión solidaria y cooperativa al hacer que el ser humano escapara de sí mismo, para existir verdaderamente; describiendo que el trabajo deja de ser abstracto para devenir en concreto y, al superar sus propias necesidades, contribuye a superar las necesidades de los demás. Smith (1776) y Ricardo (1817) resaltan la importancia del trabajo como fuente generadora de riqueza, cuyas afirmaciones, ulteriormente, sentarían las bases de la teoría del valor-trabajo, retomadas posteriormente por la doctrina marxista.

Con el auge de la revolución industrial en la segunda mitad del siglo XIX, brota el empleo industrial a gran escala bajo la modalidad de trabajo asalariado. La fuerza de trabajo como mercancía es intercambiada en el mercado laboral por un salario mediado generalmente por un contrato de trabajo; perdiendo así su carácter de identidad personal y de integración social; desde esta nueva perspectiva, el trabajo se ancla a la obtención de un beneficio puramente económico. 
Neffa (1999) citando a Fouquet (1998) asevera que todo trabajo no es un empleo: se puede trabajar y no tener un empleo, como es el caso de la esposa o madre de familia que no percibe una remuneración por las tareas domésticas que realiza.

A mediados de la década de los setenta el empleo en el mundo desarrollado sufrió una sustancial transformación. Las empresas orientaron mayormente sus esfuerzos y su capacidad a la reorganización interna introduciendo innovaciones tecnológicas en los procesos productivos, el producto, la distribución y la comercialización de los bienes y servicios. El desarrollo de la técnica como respuesta a los problemas de baja productividad y de pérdida de competitividad empresarial, modificó radicalmente las relaciones laborales y salariales. Las empresas centraron sus esfuerzos en la reducción de costos, en particular, los costos laborales directos e indirectos, inclinándose por la producción de bienes con alta mecanización, marcada división técnica del trabajo y la subcontratación como medio de vinculación de la fuerza de trabajo. La alta rivalidad en los mercados y la excesiva competencia interna y externa jalonada por la globalización, flexibilizaron y precarizaron el empleo a nivel mundial y se profundizó el desempleo de manera alarmante. Hoy, recogiendo el pensamiento de la Organización Internacional del Trabajo (OIT), la instauración del trabajo decente como lucha por la dignidad humana parece estar seriamente amenazado por el proceso de liberalización comercial e integración de las economías en un mercado único e interdependiente llamado globalización económica.

\section{Algunas reflexiones sobre el trabajo decente y la precariedad del empleo.}

La OIT (1999) como abanderada del trabajo decente en el mundo lo define como el conjunto de actividades humanas, remuneradas o no, que producen bienes o servicios en una economía, o que satisfacen las necesidades de una comunidad o proveen los medios de sustento necesarios para los individuos; en cambio, el empleo es definido como trabajo efectuado a cambio de pago o remuneración. Para la OIT el trabajo decente es el "trabajo productivo en condiciones de libertad, equidad, seguridad y dignidad, en el cual los derechos son protegidos y que cuenta con remuneración adecuada y protección social" (OIT, 1999a, pág. 4). El trabajo decente se orienta a cuatro objetivos estratégicos, así: 1) la promoción de los derechos laborales; 2) la promoción del empleo; 3) la protección social contra las situaciones de vulnerabilidad; y 4) el fomento del diálogo social (OIT, 1999a). Cabe mencionar, que "el término trabajo decente es un concepto en 
construcción, de carácter integrador y de amplio contenido ético y de justicia social" (Gálvez et al, 2011, pág. 80)

Para Somavía (2014), el trabajo decente se fundamenta en cuatro pilares fundamentales: a) el trabajo o empleo mismo; b) en los derechos en el trabajo (libertad de asociación, derecho a negociación colectiva y erradicación del trabajo forzoso, la discriminación y el trabajo infantil); c) en la noción de seguridad y protección social (rechazo a las situaciones de inseguridad y empleo precario); y, por último, d) en la idea de representación y diálogo social (pág. 25).

Román \& Cervantes (2013, págs. 49-50) en atención a los postulados del trabajo de decente de la OIT (1999), puntualizan los aspectos que se combinan en la conceptualización de un empleo decente con propósitos de medición, análisis y critica, los cuales se utilizarán más adelante en este artículo para la posterior construcción del índice de trabajo decente (véase Tabla 2).

\section{Tabla 2}

Dimensiones y condiciones del trabajo decente

\begin{tabular}{|c|c|c|c|}
\hline Dimensión & Conceptualización & Indicador & Criterios \\
\hline Económica & $\begin{array}{l}\text { Ingresos } \\
\text { suficientes }\end{array}$ & Salario mínimo & $\begin{array}{l}\text { Se considera precario cuando el } \\
\text { salario es menor al que garantiza un } \\
\text { nivel mínimo necesario para tener } \\
\text { acceso a alimentación, vestido, } \\
\text { educación, salud y vivienda. }\end{array}$ \\
\hline \multirow[b]{3}{*}{ Normativa } & \multirow{3}{*}{$\begin{array}{l}\text { Promoción de los } \\
\text { derechos del } \\
\text { trabajador }\end{array}$} & Contrato de trabajo & $\begin{array}{l}\text { Las relaciones de trabajo sin contrato } \\
\text { vulneran y desprotegen a los } \\
\text { trabajadores. }\end{array}$ \\
\hline & & Temporalidad & $\begin{array}{l}\text { La temporalidad como un fenómeno } \\
\text { de inestabilidad laboral. }\end{array}$ \\
\hline & & $\begin{array}{l}\text { Duración de la } \\
\text { jornada }\end{array}$ & $\begin{array}{l}\text { Jornada laboral completa, estable y } \\
\text { remunerada garantiza buenas } \\
\text { condiciones a los trabajadores; en } \\
\text { cambio, jornadas inestables e } \\
\text { incompletas precarizan las } \\
\text { condiciones de trabajo. }\end{array}$ \\
\hline
\end{tabular}




\begin{tabular}{|c|c|c|c|}
\hline \multirow{3}{*}{$\begin{array}{l}\text { Seguridad } \\
\text { social }\end{array}$} & \multirow{3}{*}{$\begin{array}{l}\text { Protección social } \\
\text { del trabajador }\end{array}$} & $\begin{array}{c}\text { Acceso a la } \\
\text { seguridad social }\end{array}$ & $\begin{array}{l}\text { La falta de acceso a la seguridad } \\
\text { social precariza las condiciones de } \\
\text { trabajo. }\end{array}$ \\
\hline & & $\begin{array}{l}\text { Prestaciones } \\
\text { sociales }\end{array}$ & $\begin{array}{l}\text { Un bajo nivel de } \\
\text { sociales fomenta la precariodad } \\
\text { laboral. }\end{array}$ \\
\hline & & $\begin{array}{c}\text { Nivel de } \\
\text { sindicalización }\end{array}$ & $\begin{array}{l}\text { Un bajo nivel de sindicalización } \\
\text { actúa en detrimento de la } \\
\text { representatividad de los trabajadores } \\
\text { y debilita su poder de negociación } \\
\text { colectiva. }\end{array}$ \\
\hline
\end{tabular}

Fuente: Román y Cervantes (2013), pág. 50.

A partir de los procesos de liberalización económica y profundización de la globalización, la flexibilización del mercado laboral y la precarización del empleo en el mundo capitalista se han vuelto más notorias. El desempleo no es solo un asunto de extrema preocupación para quien lo padece, sino también para la sociedad y los gobiernos de turno; la teoría económica neoclásica sitúa su atención en el análisis de las rigideces del mercado de trabajo como obstáculo al crecimiento económico y a la generación de empleo; argumentando que la flexibilización laboral permite a las empresas adaptarse de forma rápida a los cambios de la demanda y a las fluctuaciones del ciclo a través de la reducción de costos y la mayor movilidad de los trabajadores, lo cual repercute en aumentos de productividad y una mejora ostensible de la competitividad empresarial. Así pues, empresas más pequeñas y más eficientes se desenvuelven mejor en mercados altamente competitivos, cuya mayor producción conduce necesariamente a la generación de mayores puestos de trabajo; en suma, la tesis neoliberal se preconiza como: ¡Precario, pero con empleo!

\section{Metodología}

Para la determinación de la muestra estadística se analizaron algunos registros históricos de las antiguas Oficinas de Planeación y Registro Académico de la Universidad de Nariño y una base de datos de los egresados del Programa de Economía con corte a 9 de febrero de 2021 proporcionada por el Centro de Informática de la Universidad de Nariño. En los archivos históricos se reportan 128 egresados (76 egresados sin título y 52 graduados) en el periodo 1973-II-1982-I. El total de egresados del Programa de Economía con corte a 2020-II es de 2.183, con el 96,24\% egresados de 
la sede Pasto, 1,15\% de la Extensión de Ipiales y 2,61\% de la Extensión de Tumaco. Del total de egresados el 50,07\% corresponde a hombres y 49,93\% a mujeres, reportándose $1.824(83,6 \%)$ economistas graduados. Los diez primeros economistas graduados (6 mujeres y 4 hombres) se registran en el periodo 1979-I, con una tasa de graduación del 50\% (de los 59 matriculados en 1973-II, 20 egresaron en 1979-I y 10 se graduaron en el mismo periodo, como parte de la primera promoción, como se indica en la Tabla 3. 


\section{Tabla 3}

Egresados en el Programa de Economía 1973-II - 2020-II

\begin{tabular}{|c|c|c|c|c|c|c|c|c|c|}
\hline \multirow[b]{2}{*}{ Sede/Extensión } & \multirow[b]{2}{*}{ Sexo } & \multicolumn{5}{|c|}{ Estado actual } & \multirow[b]{2}{*}{$\%$} & \multirow[b]{2}{*}{ Total } & \multirow[b]{2}{*}{$\%$} \\
\hline & & Graduados & $\%$ & Egresados & $\%$ & Regulares & & & \\
\hline \multirow{3}{*}{ Pasto } & Hombre & 870 & 39,85 & 182 & 8,34 & 1 & 0,05 & 1.053 & 48,24 \\
\hline & Mujer & 877 & 40,17 & 171 & 7,83 & 0 & 0,00 & 1.048 & 48,01 \\
\hline & Total & 1.747 & 80,03 & 353 & 16,17 & 1 & 0,05 & 2.101 & 96,24 \\
\hline \multirow{3}{*}{ Ipiales } & Hombre & 16 & 0,73 & 1 & 0,05 & 0 & 0,00 & 17 & 0,78 \\
\hline & Mujer & 8 & 0,37 & 0 & 0,00 & 0 & 0,00 & 8 & 0,37 \\
\hline & Total & 24 & 1,10 & 1 & 0,05 & 0 & 0,00 & 25 & 1,15 \\
\hline \multirow{3}{*}{ Tumaco } & Hombre & 21 & 0,96 & 2 & 0,09 & 0 & 0,00 & 23 & 1,05 \\
\hline & Mujer & 32 & 1,47 & 2 & 0,09 & 0 & 0,00 & 34 & 1,56 \\
\hline & Total & 53 & 2,43 & 4 & 0,18 & 0 & 0,00 & 57 & 2,61 \\
\hline \multirow{3}{*}{ Total } & Hombre & 907 & 41,55 & 185 & 8,47 & 1 & 0,05 & 1.093 & 50,07 \\
\hline & Mujer & 917 & 42,01 & 173 & 7,92 & 0 & 0,00 & 1.090 & 49,93 \\
\hline & Total & 1.824 & 83,55 & 358 & 16,40 & 1 & 0,05 & 2.183 & 100,00 \\
\hline
\end{tabular}

Fuente: elaboración propia con corte a 9 de febrero de 2021. 
Esta investigación tomó como marco muestral a los 1.824 economistas titulados en el periodo comprendido entre 1979-I y 2020-II. A partir de este universo, se calculó una muestra estadística de 316 personas para la aplicación de un cuestionario en línea de indagación de condiciones ocupacionales. El diseño metodológico se apoyó en dos instrumentos básicos de recolección y análisis de información primaria, a saber: una encuesta de corte cuantitativo y una entrevista individual semiestructurada de carácter cualitativo. El cuestionario se aplicó entre mayo y junio de 2021, aunque esta encuesta fue enviada a los 734 contactos $^{1}$ disponibles en la base de datos arriba mencionada, también se utilizó el método de bola de nieve (un graduado busca a otro graduado) para contactar a más personas. A través de mensajes por correo electrónico y llamadas telefónicas, se logró que 294 economistas graduados contestaran la encuesta; una encuesta fue respondida de modo incompleto, la cual fue desechada posteriormente, para un total de 293 cuestionarios válidos. Guba \& Lincoln (2002) aseveran que en el paradigma epistemológico constructivista e interpretativista, la naturaleza variable y personal (intramental) de las construcciones sociales sugiere que las construcciones individuales pueden ser producidas y refinadas sólo mediante la interacción entre el investigador y quienes responden, dichas construcciones se interpretan utilizando técnicas hermenéuticas convencionales y se contrastan mediante un intercambio dialéctico (pág. 128). Para ampliar la comprensión del objeto de estudio y acudiendo a las técnicas de investigación cualitativa, se aplicaron 30 entrevistas virtuales a economistas de diferentes cohortes, con una duración promedio de una hora por entrevista, efectuadas en horarios diurno y nocturno, de conformidad con la disponibilidad de tiempo de los entrevistados; este proceso se surtió entre los meses de junio y julio de 2021 (véase Tabla 4).

\footnotetext{
${ }^{1}$ La base de datos de egresados proporcionada por el Centro de Informática de la Universidad de Nariño es bastante restringida; por ejemplo, no se reporta información relacionada con correo electrónico y números de celulares para los economistas graduados en la década de los ochenta y mediados de los noventa, puesto que la telefonía móvil y el uso de internet se masificó a finales del siglo XX. En los directorios disponibles aparecen algunos números de telefonía fija, muchos de ellos se reportan hoy, como inactivos.
} 


\section{Tabla 4}

Ficha Técnica de la Investigación

\begin{tabular}{|c|c|c|}
\hline Características & $\begin{array}{l}\text { Encuesta a Graduados } \\
\text { Programa de Economía }\end{array}$ & $\begin{array}{l}\text { Entrevistas a Graduados } \\
\text { Programa de Economía }\end{array}$ \\
\hline Universo & $\begin{array}{l}\text { 1.824 economistas graduados a } \\
\text { partir de } 1979-\text { I. }\end{array}$ & N.A. \\
\hline Unidad muestral & Persona (economista graduado) & $\begin{array}{l}\text { Economista graduado } \\
\text { (informante) }\end{array}$ \\
\hline Ámbito geográfico & $\begin{array}{l}\text { Departamento de Nariño, } \\
\text { Colombia }\end{array}$ & $\begin{array}{l}\text { Departamento de Nariño, } \\
\text { Colombia }\end{array}$ \\
\hline $\begin{array}{l}\text { Método de } \\
\text { recolección de } \\
\text { información }\end{array}$ & Encuesta & Entrevista personal \\
\hline $\begin{array}{l}\text { Procedimiento de } \\
\text { muestreo }\end{array}$ & Muestreo aleatorio simple & Muestreo teórico por saturación \\
\hline $\begin{array}{l}\text { Tamaño de la } \\
\text { muestra }\end{array}$ & $\begin{array}{l}316 \text { ( } 293 \text { encuestas } \\
\text { contestadas) }\end{array}$ & $\begin{array}{l}30 \text { entrevistas } \\
\text { semiestructuradas ( } 15 \text { a } \\
\text { mujeres y } 15 \text { a hombres). }\end{array}$ \\
\hline Nivel de confianza & $\begin{array}{l}95 \% ; Z=1,96 ; p=q=50 \% \\
e=5 \%\end{array}$ & N.A. \\
\hline Trabajo de campo & Mayo a junio de 2021 & Junio a julio de 2021 \\
\hline
\end{tabular}

N.A: No aplica

Fuente: elaboración propia.

En el procesamiento y análisis de los datos cuantitativos se utilizó estadística descriptiva y el test del Chi cuadrado $\left(\chi^{2}\right)$ de Pearson a partir de la elaboración de tablas de contingencia con un Alfa de Cronbach de 0,69. En el análisis de rentas salariales de los economistas por sexo se utilizó dos modelos econométricos, los cuales permiten comprender los factores que explican el salario y la existencia o no de brechas salariales entre hombres y mujeres. La medición del trabajo decente se determinó a través de un índice sintético inspirado en la metodología de la OIT (1999).

Las entrevistas semiestructuradas permitieron interpretar el significado que los informantes dan a cuestiones, tales como: su desempeño profesional, el nivel de satisfacción con el trabajo actual, las 
condiciones del sitio de trabajo, las dificultades en la búsqueda de empleo, el fracaso laboral, la relación entre el empleo actual y la formación académica, entre otros.

\section{Resultados}

\section{Condiciones de trabajo de los economistas de la Universidad de Nariño.}

La precariedad describe de manera general el deterioro progresivo de las condiciones ocupacionales de la clase trabajadora; así pues, su significado ha sido objeto de análisis por diferentes autores dan origen a conceptualizaciones, tales como: fragmentación (Offe, 1992), individualización (Castel \& Goldstein, 1994), desafiliación (Castel, 1995) y flexiprecarización (Sotelo, 1997). Para Castel (1998), la globalización imperante en el modelo económico actual aboga por la desregulación de las relaciones laborales para la disminución del costo de la fuerza de trabajo y, por ende, los costos de producción y el aumento de la productividad laboral como condiciones esenciales de la competitividad empresarial y territorial.

Por su parte, De La Garza (2000), no duda en señalar, que las reformas laborales son causantes de la precarización del empleo, los bajos salarios y la progresiva violación y desmonte de los derechos laborales. La reducción de los costos de despido y la eliminación paulatina de los deberes de los empleadores, contribuyen a la mayor acumulación de capital y a la reproducción de la desigualdad económica a costa del malestar de la clase obrera. Agregando a lo anterior, Standing (2011) afirma que, en la precarización, "el sujeto es conducido a vivir una existencia frágil en el presente, sometido a incertidumbres acerca del futuro, con una identidad insegura y carente de sentido de desarrollo posible" (págs.16-18); en otras palabras, el precario es un ser desesperanzado.

\section{¿Tienen los economistas graduados de la Universidad de Nariño un trabajo decente?}

De acuerdo con Gálvez et al, 2011, no existe una única metodología para medir el trabajo decente que sea universalmente aceptada. Los estudios de medición y caracterización del trabajo decente, aunque consideran algunas dimensiones y criterios en común, suelen utilizar algunas variantes para aproximarse a una mejor explicación. Farné (2003) sostiene que la medida más común de la calidad del empleo está constituida por los salarios, en la lógica económica de que a mayores rentas 
del trabajo, el consumidor podrá acceder a una canasta más amplia de bienes y servicios, alcanzando un mayor nivel de bienestar material. Los testimonios y significados aportados por los informantes en las entrevistas realizadas, señalan que, el salario recibido a cambio de su fuerza de trabajo no es del todo acorde con su formación profesional y aspiraciones personales; sin embargo, expresan sentirse "a gusto con el trabajo realizado y con el ambiente, en el que este se ejecuta". En este sentido, la motivación es superior a la remuneración monetaria; y la tranquilidad supera a la felicidad.

Para la medición de la calidad del empleo de los economistas graduados de la Universidad de Nariño se aplicó un índice sintético utilizado por Farné (2003) en la medición del empleo decente en Colombia, fundamentado en la conceptualización de la OIT (1999), el cual toma cuatro variables básicas, a saber: los ingresos laborales, la modalidad de contratación, la afiliación a la seguridad social y la jornada de trabajo. El ingreso laboral se clasifica según el número de veces que el monto de dicho ingreso contiene el valor del salario mínimo mensual legal vigente (smmlv). Se consideraron tres niveles, así: menos de 1,5 veces el smmlv ${ }^{2}$, entre 1,5 y $3 \mathrm{smmlv}$ y más de 3 veces el smmlv. La modalidad contractual incluye tres alternativas posibles, así: existencia de un contrato laboral escrito a término indefinido, existencia de un contrato laboral escrito a término fijo y ausencia de contrato escrito (contrato verbal). En lo atinente a la seguridad social se consideró la afiliación del trabajador a los sistemas de salud, pensión y riesgos laborales en conjunto, o a uno sólo de ellos.

Finalmente, conforme a lo establecido en el artículo 161 del Código Sustantivo de Trabajo, la duración máxima de la jornada ordinaria de trabajo es de ocho (8) horas al día y cuarenta y ocho (48) horas a la semana, con la salvedad, de que con la expedición de la reciente Ley 2101 del 15 de julio de 2021, se reduce la jornada laboral semanal de manera gradual, sin disminuir el salario de los trabajadores colombianos, ni afectar los derechos adquiridos y garantías de la clase trabajadora; de acuerdo al artículo 3 de esta ley, la reducción de la jornada laboral empezará el 15

\footnotetext{
${ }^{2}$ El salario mínimo mensual legal vigente (SMMLV) para 2021 es de \$ 908.526; este valor no incluye el subsidio de transporte de \$106.454. De acuerdo con Farné (2003), un ingreso básico laboral de 1.5 veces el SMLV representaba el $75 \%$ del valor de la canasta de consumo básico para una familia de cuatro personas en Colombia. Según el DANE, la canasta familiar es el conjunto de bienes y servicios que cualquier familia colombiana adquiere de forma habitual. En ella solo se incluyen alimentos y artículos de primera necesidad, productos y servicios relacionados con la salud, educación, vivienda, vestuario, transporte, servicios públicos, diversión y entretenimiento, cultura y comunicaciones.
} 
de julio de 2023 y finalizará el 15 de julio de 2026, a partir de esta fecha, la jornada de trabajo será de cuarenta y dos (42) horas semanales. Aunque en el articulado de la citada ley no se menciona su fin esencial, se entiende que su verdadero espíritu es incentivar gradualmente la generación de nuevos puestos de trabajo, aunque su efecto puede ser adverso, al incentivar en el productor la progresiva sustitución de trabajo por capital presionando el aumento en el desempleo.

A las cuatro dimensiones analizadas se les asignó un peso porcentual de conformidad con su nivel de importancia; por ejemplo, los ingresos adecuados tienen un peso de 40\%, 25\% a la estabilidad en el trabajo, $25 \%$ a la seguridad social y $10 \%$ a la jornada de trabajo. A su vez, este porcentaje fue redistribuido en cada uno de los criterios analizados conforme a la metodología propuesta por Farné (2003) para Colombia. Tomando la escala empleada por el PNUD para la clasificación de los países según el Índice de Desarrollo Humano (IDH) valorada de 0 a 100, el Índice de Calidad del Trabajo (ICT) se clasifica, así: 0 a 49 corresponde a un ICT bajo; 50 a 79 a un ICT medio; y 80 a 100 a un ICT alto. El ICT obtenido es de 62,0 para dependientes y 49,9 para independientes; un ICT general de 47,41 y un ICT de 48,62 para hombres y 45,96 para mujeres. Estos resultados muestran que los economistas dependientes tienen mejores condiciones ocupacionales en comparación con los independientes (trabajadores por cuenta propia, empresarios y trabajadores familiares sin remuneración) y que las condiciones de trabajo de los hombres son ligeramente superiores a las condiciones laborales de los economistas en general y de las mujeres en particular; aunque es preciso mencionar que los tres últimos valores se sitúan en el rango de calidad de trabajo bajo. Estos resultados muestran que el empleo actual de los economistas de la Universidad de Nariño no cumple con la totalidad de los estándares señalados por la OIT, siendo consistentes con los hallazgos del estudio sobre la calidad del empleo en Colombia elaborado por Farné (2003), donde se concluye que "los trabajadores dependientes están en mejores condiciones ya que su respectivo índice se sitúa en casi 43,8 puntos. A pesar que éste no es un puntaje suficiente para "pasar el año", es notablemente superior al de los trabajadores independientes que apenas obtienen 27,5 puntos" (pág. 26). Igualmente, Mora \& Ulloa (2011) señalan que el índice de calidad del empleo en las principales ciudades colombianas se encuentra entre 46,8 puntos porcentuales para trabajadores dependientes y 48,7 puntos porcentuales para trabajadores independientes; estos 
puntajes se sitúan por debajo del $60 \%$, considerado como límite inferior para tener un empleo de calidad (véase Tabla 5). 


\section{Tabla 5}

Índice de Calidad de Trabajo (ICT) según metodología OIT (1999)

\begin{tabular}{|c|c|c|c|c|c|c|c|c|}
\hline \multirow[b]{2}{*}{ Dimensión } & \multirow[b]{2}{*}{ Variable } & \multirow[b]{2}{*}{ Criterio } & \multirow[b]{2}{*}{ Condición } & \multicolumn{3}{|c|}{$\begin{array}{c}\text { Calidad del trabajo por } \\
\text { sexo }\end{array}$} & \multicolumn{2}{|c|}{$\begin{array}{c}\text { Calidad del trabajo por tipo } \\
\text { de relación laboral }\end{array}$} \\
\hline & & & & $\begin{array}{c}\text { Índice } \\
\text { de } \\
\text { Calidad } \\
\text { del } \\
\text { Trabajo } \\
\text { General }\end{array}$ & $\begin{array}{c}\text { Índice } \\
\text { de } \\
\text { Calidad } \\
\text { del } \\
\text { Trabajo } \\
\text { Hombres }\end{array}$ & $\begin{array}{c}\text { Indice } \\
\text { de } \\
\text { Calidad } \\
\text { del } \\
\text { Trabajo } \\
\text { Mujeres }\end{array}$ & $\begin{array}{c}\text { Índice de } \\
\text { Calidad del } \\
\text { Empleo } \\
\text { Dependientes }\end{array}$ & $\begin{array}{c}\text { Índice de } \\
\text { Calidad del } \\
\text { Empleo } \\
\text { Independientes }\end{array}$ \\
\hline \multirow{3}{*}{$\begin{array}{l}\text { Ingresos } \\
\text { adecuados }\end{array}$} & \multirow{3}{*}{$\begin{array}{l}\text { Ingreso } \\
\text { laboral } \\
\text { mensual }\end{array}$} & $\begin{array}{l}\text { Más de } 3 \\
\text { SMMLV }\end{array}$ & $\begin{array}{l}\text { Ingreso medio- } \\
\text { alto }\end{array}$ & 10,35 & 12,18 & 8,25 & 15,57 & 13,02 \\
\hline & & $\begin{array}{l}\text { Entre } 1,5 \text { y } 3 \\
\text { SMMLV }\end{array}$ & Ingreso bajo & 4,10 & 3,61 & 4,64 & 5,19 & 5,81 \\
\hline & & $\begin{array}{l}\text { Menos de } 1,5 \\
\text { SMMLV }\end{array}$ & $\begin{array}{l}\text { Ingreso } \\
\text { precario }\end{array}$ & 0 & 0 & 0 & 0,00 & 0,00 \\
\hline \multirow{3}{*}{$\begin{array}{l}\text { Estabilidad } \\
\text { en el trabajo }\end{array}$} & \multirow{3}{*}{$\begin{array}{l}\text { Contrato } \\
\text { laboral }\end{array}$} & \multirow{3}{*}{$\begin{array}{l}\text { Duración del } \\
\text { contrato }\end{array}$} & $\begin{array}{l}\text { Contrato } \\
\text { escrito a } \\
\text { término } \\
\text { indefinido }\end{array}$ & 5,12 & 4,85 & 5,43 & 7,78 & 0,00 \\
\hline & & & $\begin{array}{l}\text { Contrato } \\
\text { escrito a } \\
\text { término fijo. }\end{array}$ & 2,15 & 2,32 & 1,96 & 5,19 & 0,00 \\
\hline & & & $\begin{array}{l}\text { Ausencia de } \\
\text { contrato escrito } \\
\text { (contrato } \\
\text { verbal). }\end{array}$ & 0,00 & 0,00 & 0,00 & 0,00 & 0,00 \\
\hline
\end{tabular}




\begin{tabular}{|c|c|c|c|c|c|c|c|c|}
\hline \multirow{5}{*}{$\begin{array}{l}\text { Seguridad } \\
\text { social }\end{array}$} & \multirow{5}{*}{$\begin{array}{l}\text { Afiliación } \\
\text { a salud, } \\
\text { pensión y } \\
\text { riesgos } \\
\text { laborales. }\end{array}$} & $\begin{array}{l}\text { Afiliación al } \\
\text { sistema de salud, } \\
\text { pensiones y } \\
\text { riesgos laborales. }\end{array}$ & Cobertura total & 18,53 & 18,38 & 18,65 & 12,97 & 11,39 \\
\hline & & $\begin{array}{l}\text { Únicamente } \\
\text { afiliación a salud. }\end{array}$ & $\begin{array}{l}\text { Cobertura } \\
\text { parcial }\end{array}$ & 0,00 & 0,00 & 0,00 & 0,00 & 0,00 \\
\hline & & $\begin{array}{l}\text { Únicamente } \\
\text { afiliación a } \\
\text { pensión. }\end{array}$ & $\begin{array}{l}\text { Cobertura } \\
\text { parcial }\end{array}$ & 0,00 & 0,00 & 0,00 & 0,00 & 0,00 \\
\hline & & $\begin{array}{l}\text { Únicamente } \\
\text { afiliación a } \\
\text { riesgos laborales } \\
\text { (ARL). }\end{array}$ & $\begin{array}{l}\text { Cobertura } \\
\text { parcial }\end{array}$ & 0,00 & 0,00 & 0,00 & 0,00 & 0,00 \\
\hline & & $\begin{array}{l}\text { Ninguna } \\
\text { afiliación }\end{array}$ & Sin cobertura & 0,00 & 0,00 & 0,00 & 0,00 & 0,00 \\
\hline \multirow{3}{*}{$\begin{array}{l}\text { Jornada de } \\
\text { trabajo }\end{array}$} & \multirow{3}{*}{$\begin{array}{l}\text { Número de } \\
\text { horas de } \\
\text { trabajo } \\
\text { semanales }\end{array}$} & Hasta 48 horas & Jornada legal & 7,17 & 7,29 & 7,03 & 5,19 & 10,66 \\
\hline & & Más de 48 horas & $\begin{array}{l}\text { Jornada } \\
\text { excesiva }\end{array}$ & 0,00 & 0,00 & 0,00 & 0,00 & 0,00 \\
\hline & & Total & & 47,41 & 48,62 & 45,96 & 62,0 & 40,9 \\
\hline
\end{tabular}

Fuente: elaboración propia a partir de los resultados de la encuesta aplicada a los graduados, mayo de 2021. 
Farné (2013) en el estudio sobre la calidad del empleo en 23 ciudades colombianas elaborado por el Observatorio del Mercado de Trabajo y la Seguridad Social de la Universidad Externado de Colombia, concluye que el índice de calidad de empleo nacional se ubicó en 38,1 en 2010 y 34,5 en 2013, corroborando una vez más, "la baja calidad promedio del empleo colombiano" (pág. 22). La persistencia de la precariedad del empleo en Colombia parece estar asociada con los efectos de la apertura económica implantada en la década de los noventa con la consecuente flexibilización del mercado laboral y el deterioro de las condiciones de trabajo; en especial, el incremento de la informalidad, la proliferación de las profesiones liberales y el rebusque como medio de subsistencia.

\section{Discriminación en el mercado de trabajo}

McConnell \& Brue (1997) sostienen que existe discriminación económica cuando las mujeres o los trabajadores pertenecientes a grupos minoritarios con la misma capacidad, nivel de estudios, formación y experiencia laboral, reciben un trato inferior en la contratación, el acceso a una ocupación, los ascensos, el salario o las condiciones de trabajo. Estos autores definen claramente cuatro tipos de discriminación, así: discriminación salarial, la cual significa que las mujeres ganan menos que los hombres por realizar un trabajo idéntico o similar; discriminación en el empleo, cuando la carga del desempleo descansa en mayor proporción en las mujeres; discriminación ocupacional, significa que las mujeres han sido excluidas total o parcialmente de algunas ocupaciones, aunque sean tan capaces como los hombres de realizar estos trabajos y, en cambio, están concentradas, en otras ocupaciones para las que suelen estar excesivamente cualificadas y; discriminación en la adquisición de capital humano, cuando las mujeres tienen menos acceso a las oportunidades que aumentan la productividad, como la educación formal y la educación para el trabajo.

\section{Discriminación salarial}

En el estudio de prospectiva con énfasis regional para los programas de economía de Colombia realizado por la Asociación Colombiana de Facultades, Programas y Departamentos de Economía (AFADECO, 2019), se señala que el 63,6\% de los economistas egresados en Colombia obtienen un salario entre \$ 2 y \$ 3 millones y, el 35,8\% entre \$ 3 y \$ 4 millones. Por su parte, el 20,8\% de 
los economistas graduados de la Universidad de Nariño devengan entre \$1.817.052 y $\$ 2.725 .578$ ( 2 a 3 smmlv), el 19,8\% entre $\$ 908.526$ y $\$ 1.817 .052$ ( 1 a 2 smmlv) y el $16,0 \%$ entre $\$ 2.725 .578$ y $\$ 3.634 .104$ ( 3 a 4 smmlv) y tan solo el $1,4 \%$ recibe una remuneración igual o superior a $\$$ 7.268.208. En el extremo inferior, se ubica el 4,1\% de los economistas con un salario igual o inferior a \$ 908.526 (un smmlv). El 51,56\% de los economistas de la Universidad de Nariño tienen ingresos laborales entre 1 y 3 smmlv y el 27,34\% reciben a cambio de su fuerza de trabajo, entre 3 y 4 smmlv; cuyas rentas laborales son más bajas en comparación con las cifras comentadas arriba.

El salario mensual promedio de un economista graduado en la Universidad de Nariño es de \$ 3.119.034 (\$3.383.591 para hombres y \$2.827.787 para mujeres), es el salario de los hombres un 19,7\% más alto que el de las mujeres y un 8,5\% más elevado que el salario medio. En cuanto a la concentración de los ingresos, el índice de GINI señala que no existe una marcada desigualdad salarial (0,311 en comparación con el 0,513 para Colombia en 2019, según el Banco Mundial) y la concentración de ingresos es baja, muy similar entre mujeres $(0,302)$ y hombres $(0,308)$, como se muestra en la Tabla 6 .

\section{Tabla 6}

Estadísticas descriptivas del salario e índice de desigualdad de GINI

\begin{tabular}{lcccccc}
\hline \multicolumn{1}{c}{ Estadísticas } & Obs. & Media & Mediana & $\begin{array}{c}\text { Desviación } \\
\text { estándar }\end{array}$ & Mínimo & Máximo \\
\hline General & 254 & 3.119 .034 & 2.271 .315 & 1.790 .702 & 908.526 & 7.268 .208 \\
Hombres & 136 & 3.383 .591 & 3.179 .841 & 1.905 .596 & 908.526 & 7.268 .208 \\
Mujeres & 120 & 2.827 .787 & 2.271 .315 & 1.602 .509 & 908.526 & 7.268 .208 \\
$\begin{array}{l}\text { Índice de GINI } \\
\text { General }\end{array}$ & 0,31063985 & & & & & \\
$\begin{array}{l}\text { Indice de GINI } \\
\begin{array}{l}\text { Hombres } \\
\text { Índice de GINI }\end{array} \\
\text { Mujeres }\end{array}$ & 0,30825011 & & & & & \\
Fuente: Elaboración propia. & 0,30199687 & & & & & \\
\hline
\end{tabular}


El análisis de la discriminación salarial de las mujeres con respecto a los hombres se soporta en la construcción de un índice de segregación como el sugerido por McConnell \& Brue ( 1997), aplicado este, a los sectores público y privado. En la Tabla 7, en general, se aprecia que las diferencias salariales son mínimas; en particular, en el sector público; observándose una diferencia en el rango de ingresos entre 1 y 2 smmlv, a favor de los hombres, siendo más pronunciada en el sector privado. El índice de segregación es de 19,52\% en el sector público y de 22,03\% en el sector privado, con un mayor valor en los ingresos que oscilan entre 1 y 2 smmlv; situándose los hombres, en una posición salarial más favorable.

\section{Tabla 7}

Índice de discriminación salarial por sexo

\begin{tabular}{|c|c|c|c|c|c|c|}
\hline \multirow[b]{2}{*}{ Ingresos laborales } & \multicolumn{3}{|c|}{ Sector Público } & \multicolumn{3}{|c|}{ Sector Privado } \\
\hline & $\begin{array}{c}(\mathrm{A}) \\
\text { Hombres } \\
(\%)\end{array}$ & $\begin{array}{c}(\mathrm{B}) \\
\text { Mujeres } \\
(\%)\end{array}$ & $\begin{array}{c}(\mathrm{C})=(\mathrm{A})- \\
(\mathrm{B}) \\
\text { Diferencias } \\
\text { absolutas }(\%)\end{array}$ & $\begin{array}{c}(\mathrm{A}) \\
\text { Hombres } \\
(\%)\end{array}$ & $\begin{array}{c}(\mathrm{B}) \\
\text { Mujeres } \\
(\%)\end{array}$ & $\begin{array}{c}(\mathrm{C})=(\mathrm{A})- \\
(\mathrm{B}) \\
\text { Diferencias } \\
\text { absolutas } \\
(\%)\end{array}$ \\
\hline$<=\$ 908526$ & 1,52 & 0,00 & 1,52 & 7,46 & 6,06 & 1,40 \\
\hline$\$ 908.526-\$ 1.817 .052$ & 10,61 & 19,23 & 8,62 & 20,90 & 37,88 & 16,98 \\
\hline$\$ 1.817 .052-\$ 2.725 .578$ & 27,27 & 19,23 & 8,04 & 22,39 & 27,27 & 4,88 \\
\hline$\$ 2.725 .578-\$ 3.634 .104$ & 18,18 & 19,23 & 1,05 & 22,39 & 15,15 & 7,24 \\
\hline$\$ 3.634 .104-\$ 4.542 .630$ & 7,58 & 15,38 & 7,81 & 7,46 & 7,58 & 0,11 \\
\hline$\$ 4.542 .630-\$ 5.451 .156$ & 13,64 & 9,62 & 4,02 & 5,97 & 3,03 & 2,94 \\
\hline$\$ 5.451 .156-\$ 6.359 .682$ & 7,58 & 9,62 & 2,04 & 2,99 & 3,03 & 0,05 \\
\hline$\$ 6.359 .682$ a $\$ 7.268 .208$ & 4,55 & 0,00 & 4,55 & 1,49 & 0,00 & 1,49 \\
\hline$\$ 7.268 .208 \mathrm{y}+$ & 9,09 & 7,69 & 1,40 & 8,96 & 0,00 & 8,96 \\
\hline Total $(\%)$ & 100,00 & 100,00 & 39,04 & 100,00 & 100,00 & 44,05 \\
\hline
\end{tabular}

Índice de segregación por ingresos laborales sector público: $39,04 \% / 2=19,52 \%$ Índice de segregación por ingresos laborales sector privado: $44,05 \% / 2=22,03 \%$ Fuente: elaboración propia.

Una proporción significativa de mujeres $(48,98 \%)$ en posesión del título de pregrado únicamente, perciben ingresos entre 1 y 2 salarios mínimos con una diferencia de $21,53 \%$ en su contra. El $17,02 \%$ de las mujeres con título de maestría reciben entre 4 y 5 salarios mínimos con una diferencia de $9,88 \%$ a favor de las mujeres; el $22,22 \%$ de los hombres con maestría reciben entre 
4 y 5 salarios con una diferencia de 17,22\% a favor de los hombres. En general, existe una mayor concentración de los ingresos laborales a nivel de maestría de 28,3\% a favor de los hombres, 27,1\% a nivel de especialización y $23,6 \%$ a nivel de pregrado a favor de los hombres. No se tomó la formación a nivel de doctorado, puesto que los casos son muy reducidos (véase Tabla 8). 


\section{Tabla 8}

Discriminación salarial por formación posgradual

\begin{tabular}{|c|c|c|c|c|c|c|c|c|c|}
\hline \multirow[b]{2}{*}{ Ingresos laborales } & \multicolumn{3}{|c|}{ Únicamente Pregrado* } & \multicolumn{3}{|c|}{ Especialización** } & \multicolumn{3}{|c|}{ Maestría*** } \\
\hline & $\begin{array}{l}(\mathrm{A}) \\
\text { Hombres } \\
(\%)\end{array}$ & $\begin{array}{c}(\mathrm{B}) \\
\text { Mujeres } \\
(\%)\end{array}$ & $\begin{array}{c}(\mathrm{C})=(\mathrm{A})- \\
(\mathrm{B}) \\
\text { Diferencias } \\
\text { absolutas } \\
(\%)\end{array}$ & $\begin{array}{c}(\mathrm{A}) \\
\text { Hombres } \\
(\%)\end{array}$ & $\begin{array}{c}(\mathrm{B}) \\
\text { Mujeres } \\
(\%)\end{array}$ & $\begin{array}{c}(\mathrm{C})=(\mathrm{A})- \\
(\mathrm{B}) \\
\text { Diferencias } \\
\text { absolutas } \\
(\%)\end{array}$ & $\begin{array}{c}(\mathrm{A}) \\
\text { Hombres } \\
(\%)\end{array}$ & $\begin{array}{c}(\mathrm{B}) \\
\text { Mujeres } \\
(\%)\end{array}$ & $\begin{array}{c}(\mathrm{C})=(\mathrm{A})- \\
(\mathrm{B}) \\
\text { Diferencias } \\
\text { absolutas } \\
(\%)\end{array}$ \\
\hline Menos de $\$ 908.526$ & 13,73 & 6,12 & 7,60 & 0,00 & 4,26 & 4,26 & 0,00 & 0,00 & 0,00 \\
\hline \$908.526 - \$ 1.817 .052 & 27,45 & 48,98 & 21,53 & 11,90 & 21,28 & 9,37 & 30,56 & 25,00 & 5,56 \\
\hline$\$ 1.817 .052-\$ 2.725 .578$ & 29,41 & 28,57 & 0,84 & 16,67 & 19,15 & 2,48 & 19,44 & 25,00 & 5,56 \\
\hline$\$ 2.725 .578-\$ 3.634 .104$ & 15,69 & 10,20 & 5,48 & 28,57 & 19,15 & 9,42 & 13,89 & 20,00 & 6,11 \\
\hline$\$ 3.634 .104-\$ 4.542 .630$ & 3,92 & 2,04 & 1,88 & 7,14 & 17,02 & 9,88 & 22,22 & 5,00 & 17,22 \\
\hline$\$ 4.542 .630-\$ 5.451 .156$ & 1,96 & 2,04 & 0,08 & 9,52 & 10,64 & 1,11 & 8,33 & 10,00 & 1,67 \\
\hline$\$ 5.451 .156-\$ 6.359 .682$ & 0,00 & 2,04 & 2,04 & 9,52 & 6,38 & 3,14 & 5,56 & 0,00 & 5,56 \\
\hline$\$ 6.359 .682$ a $\$ 7.268 .208$ & 1,96 & 0,00 & 1,96 & 2,38 & 0,00 & 2,38 & 0,00 & 15,00 & 15,00 \\
\hline Más de $\$ 7.268 .208$ & 5,88 & 0,00 & 5,88 & 14,29 & 2,13 & 12,16 & 0,00 & 0,00 & 0,00 \\
\hline Total $(\%)$ & 100,00 & 100,00 & 47,30 & 100,00 & 100,00 & 54,20 & 100,00 & 100,00 & 56,67 \\
\hline
\end{tabular}

*Índice de segregación por ingresos laborales pregrado: 39,04\%/2 = 19,52\%

**índice de segregación por ingresos laborales especialización: 44,05\%/2 =22,03\%

***índice de segregación por ingresos laborales maestría: $56,67 \% / 2=28,34 \%$

Fuente: elaboración propia 


\section{Discriminación en el empleo.}

En cuanto a la discriminación en el empleo, las diferencias entre mujeres y hombres son mínimas. El 6,48\% de los graduados manifiesta estar buscando empleo (6,45\% de hombres y 6,52\% de mujeres). Estas cifras son significativamente menores a las tasas nacionales, aunque se debe analizar con mayor prudencia estas estadísticas, considerando que una proporción de economistas ejercen como trabajadores familiares sin remuneración y otros, particularmente mujeres, desempeñan actividades domésticas en el hogar como parte de la división sexual del trabajo. El 2,05\% de los encuestados afirman que después de graduados nunca consiguieron un empleo ( $1,37 \%$ en hombres y $0,68 \%$ en mujeres), aunque el periodo de consecución del primer trabajo fue inmediato para el 36,18\% y relativamente rápido (entre uno y seis meses) para el 31,06\%, con leves diferencias a favor de los hombres.

Esta investigación también indagó sobre el nivel de desempleo por sexo a través de la pregunta: ¿en qué ocupó usted la mayor parte del tiempo en la semana pasada? Las diferencias entre las tasas de desempleo entre hombres y mujeres son mínimas, 3,41\% en hombres y 3,07\% en mujeres para un total de $6,48 \%$. Considerando que la actual situación de pandemia ha socavado el trabajo a nivel mundial, la medición de la tasa de paro en la presente investigación también se verificó a través de la pregunta relacionada con el cargo que el encuestado ocupa actualmente. El 13,0\% de los economistas afirman estar desempleados (12,9\% en hombres y 13,0\% en mujeres), lo cual ratifica que la carga del desempleo está perfectamente balanceada entre mujeres y hombres.

\section{Discriminación por ocupación.}

En cuanto a la discriminación ocupacional por sexo, el índice de segregación ocupacional muestra el porcentaje de mujeres (o de hombres) que tendrían que cambiar de ocupación para que las mujeres estuvieran distribuidas en las ocupaciones en las mismas proporciones que los hombres. En la Tabla 9 se observa que el 26,51\% de los economistas se desempeñan como profesionales universitarios, en especial, en el sector público; el 14,86\% están dedicados a impartir formación, en particular, a nivel de educación superior y el 23,25\% ocupan cargos directivos o de confianza. Hay algunas diferencias en los cargos directivos $(5,86 \%)$ y en el cargo de docente $(8,91 \%)$ a favor de los hombres; en cambio, en los cargos operativos la diferencia de 6,35\% se inclina a favor de 
las mujeres. En conclusión, la discriminación por ocupación entre mujeres y hombres es mínima, existiendo igualdad de oportunidades laborales entre sexos.

\section{Tabla 9}

Cargo desempeñado e índice de segregación por ocupación

\begin{tabular}{lcccccccc}
\hline \multicolumn{1}{c}{$\begin{array}{c}\text { Cargo } \\
\text { desempeñado }\end{array}$} & Hombres & $\%$ & Mujeres & $\%$ & Total & $\%$ & $\begin{array}{c}\text { Diferencias } \\
\text { absolutas } \\
(\%)\end{array}$ \\
\cline { 2 - 5 } Directivo(a) & 21 & 16,03 & 12 & 10,17 & 33 & 13,25 & 5,86 \\
Jefe de área & 12 & 9,16 & 12 & 10,17 & 24 & 9,64 & 1,01 \\
Supervisor(a) & 6 & 4,58 & 2 & 1,69 & 8 & 3,21 & 2,89 \\
Técnico(a) & 4 & 3,05 & 6 & 5,08 & 10 & 4,02 & 2,03 \\
Operativo(a) & 5 & 3,82 & 12 & 10,17 & 17 & 6,83 & 6,35 \\
Profesional & 31 & 23,66 & 35 & 29,66 & 66 & 26,51 & 6,00 \\
universitario & & & & & & & \\
Profesional & 9 & 6,87 & 12 & 10,17 & 21 & 8,43 & 3,30 \\
especializado & 25 & 19,08 & 12 & 10,17 & 37 & 14,86 & 8,91 \\
Docente & 2 & 1,53 & 0 & 0,00 & 2 & 0,80 & 1,53 \\
Empleado raso & 16 & 12,21 & 15 & 12,71 & 31 & 12,45 & 0,50 \\
Otro & 131 & 100,00 & 118 & 100,00 & 249 & 100,00 & 38,38 \\
\hline \multicolumn{1}{c}{ Total } & & & & & & & \\
\hline
\end{tabular}

Índice de segregación ocupacional: $38,38 \% / 2=19,19 \%$

Fuente: elaboración propia.

Las distribuciones ocupacionales de los hombres y de las mujeres se muestran en las columnas 2 y 3 de la Tabla 10. Para que sea idéntica la distribución por ocupación laboral, el 18,80\% de las mujeres tendrían que cambiar de ocupación para que ambos sexos estuvieran distribuidos en las mismas proporciones entre las ocupaciones. Se observa una diferencia de 13,80\% en la ocupación de empleado del sector privado a favor de las mujeres, de servidor público de carrera administrativa de $8,80 \%$ a favor de los hombres y de 5,0\% en el cargo de contratista del gobierno a favor de las mujeres. 


\section{Tabla 10}

Índice de discriminación por ocupación

\begin{tabular}{lccc}
\hline \multicolumn{1}{c}{ Ocupación } & $\begin{array}{c}(\mathbf{A}) \\
\text { Hombres } \\
(\mathbf{\%})\end{array}$ & $\begin{array}{c}(\mathbf{B}) \\
\mathbf{M u j e r e s} \\
(\mathbf{\%})\end{array}$ & $\begin{array}{c}(\mathbf{C})=(\mathbf{A})-(\mathbf{B}) \\
\text { Diferencias } \\
\text { absolutas } \mathbf{( \% )}\end{array}$ \\
\hline Empleado(a) sector privado & 30,37 & 44,17 & 13,80 \\
Servidor público (libre nombramiento y & 11,85 & 9,17 & 2,69 \\
remoción). & & & \\
Servidor público (carrera administrativa) & 16,30 & 7,50 & 8,80 \\
Servidor público (cargo en provisionalidad) & 6,67 & 5,83 & 0,83 \\
Servidor público docente a término indefinido & 2,22 & 0,83 & 1,39 \\
Contratista del Gobierno en cualquiera de sus & 13,33 & 18,33 & 5,00 \\
niveles. & & & \\
Trabajador(a) independiente (cuenta propia) & 12,59 & 10,00 & 2,59 \\
Trabajador(a) familiar sin remuneración & 1,48 & 0,83 & 0,65 \\
Empresario(a) & 5,19 & 3,33 & 1,85 \\
\hline \multicolumn{1}{c}{ Total (\%) } & 100,00 & 100,00 & 37,60 \\
\hline
\end{tabular}

Índice de segregación ocupacional $=37,60 \% / 2=18,80 \%$

Fuente: elaboración propia.

\section{Discriminación por acumulación de capital humano}

La discriminación en la acumulación de capital humano se da cuando las mujeres tienen menos acceso a las oportunidades que incrementan la productividad laboral a partir de la formación y la capacitación para el trabajo y el desarrollo humano, teniendo en cuenta que la educación potencia ostensiblemente el desarrollo de capacidades, la ampliación de la libertad y la realización personal. El 43,0\% (41,94\% de hombres y 44,20\% de mujeres) de los economistas manifiestan no contar con ninguna formación posgradual, el 33,79\% alcanzaron formación en especialización a favor de las mujeres, el 21,50\% tienen formación a nivel de maestría a favor de los hombres y una proporción muy pequeña cuenta con estudios de doctorado $(1,71 \%)$ en una proporción balanceada (véase Tabla 11). 


\section{Tabla 11}

Formación posgradual (índice de segregación)

\begin{tabular}{lcccccccc}
\hline \multirow{2}{*}{$\begin{array}{c}\text { Formación } \\
\text { posgradual }\end{array}$} & Hombres & $\%$ & Mujeres & $\%$ & Total & $\%$ & $\begin{array}{c}\text { Diferencias } \\
\text { absolutas } \\
(\%) *\end{array}$ \\
\hline Ninguna & 65 & 41,94 & 61 & 44,20 & 126 & 43,00 & 2,27 \\
Especialización & 46 & 29,68 & 53 & 38,41 & 99 & 33,79 & 8,73 \\
Maestría & 41 & 26,45 & 22 & 15,94 & 63 & 21,50 & 10,51 \\
Doctorado & 3 & 1,94 & 2 & 1,45 & 5 & 1,71 & 0,49 \\
\hline \multicolumn{1}{c}{ Total } & 155 & 100,00 & 138 & 100,00 & 293 & 100,00 & 22,00 \\
\hline
\end{tabular}

*Índice de segregación: $22,0 \% / 2=11,0 \%$

Fuente: elaboración propia.

\section{Determinantes de los salarios profesionales de los economistas}

Para identificar los determinantes del salario se estimó el modelo (1) con sus respectivas pruebas de especificación y diagnóstico. El salario (en logaritmo natural) está explicado en forma negativa por la edad y de manera positiva por la experiencia profesional y la formación posgradual. La formación en maestría y doctorado son las variables que mayor aportan a los salarios; p. ej., un título de maestría incrementa el salario de los economistas en 27,30\% y un título de doctorado en 45,55\%; aunque, únicamente el 1,7\% de los economistas cuenta con formación doctoral, el 21,5\% con formación en maestría y 33,8\% con especialización. El modelo en cuestión predice que, por cada año adicional de edad, el salario se reduce en $1,39 \%$ y por cada año de experiencia profesional, el salario aumenta en 3,59\%. Así pues, la formación posgradual, en particular, a nivel de maestría y doctorado y la experiencia profesional son clave en la fijación de los salarios de los economistas graduados (véase Anexos 1 a 3.2).

$$
\begin{aligned}
& \text { lsalario }=14,6866-0,0139 * \mathrm{EDAD}+0,0359 * \mathrm{EXPE}+0,2016 * \mathrm{ESP}+0,2730 * \mathrm{MAE}+0,4555^{*} \mathrm{DOC} \\
& \begin{array}{llllll}
(0,156546)^{3} & (0,005552) & (0,006691) & (0,063249) & (0,067373) & (0,215165)
\end{array}
\end{aligned}
$$

\footnotetext{
${ }^{3}$ Los valores entre paréntesis corresponden a los errores estándar. El t estadístico se calcula como el cociente entre el coeficiente y el error estándar.
} 


\section{¿Existe una brecha salarial de género en la profesión de economista?}

El Departamento Administrativo Nacional de Estadística (DANE) señala que la estimación de la brecha salarial de género es una necesidad global como un elemento relevante para comprender las dinámicas del mercado laboral con enfoque de género (Rojas \& García, 2020). La OIT destaca en la Agenda 2030 para el Desarrollo Sostenible, el objetivo 8 sobre Trabajo Decente y Crecimiento Económico; en particular, la Meta 8.5, expresada así: "Para 2030, lograr el empleo pleno y productivo y garantizar un trabajo decente para todos los hombres y mujeres, incluidos los jóvenes y las personas con discapacidad, y la igualdad de remuneración por trabajo de igual valor" (OIT, 2021).

Blau \& Kahn (2016) y Levanon et, al (2009) citados en Rojas \& García (2020) argumentan que el análisis de las desigualdades relacionadas con el género requiere del entendimiento de variables socioeconómicas y que las variaciones del ingreso laboral se pueden explicar con factores como el nivel educativo, la etnicidad, el territorio, el nivel de ingreso, la tasa de participación, la posición ocupacional, entre otros atributos de las personas y las empresas que afecten las dinámicas del mercado laboral (pág. 7).

Para corroborar la existencia de un desequilibrio salarial de género, se estimó el modelo (2), a través del cual se concluye que la brecha salarial de género es mínima; tan solo de $0,76 \%$ de diferencia salarial por cada año de experiencia profesional (EXPE) en contra de las mujeres. Por cada año de experiencia profesional de las mujeres, su salario se reduce en $0,76 \%$ en comparación con los hombres. De otro lado, la formación posgradual en maestría, aumenta el salario de las mujeres en 32,81\% en comparación con los hombres. La edad tiene un efecto negativo en ambos sexos, por cada año adicional de edad, el salario se reduce en 1,68\% como efecto de las preferencias de los empleadores por contratar personas más jóvenes; y, por cada año de experiencia profesional en hombres y mujeres, el salario aumenta en 4,62\% (véase Anexos 2 a 4).

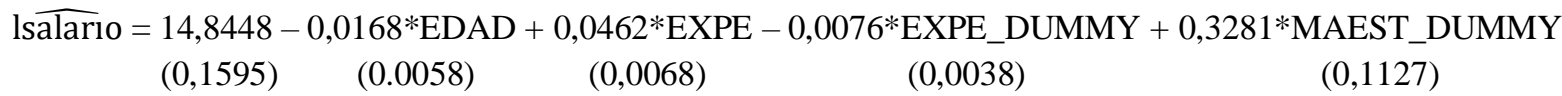




\section{Conclusiones}

La mayoría de los economistas graduados se encuentran insertados en los sectores público $(47,04 \%)$ y privado $(52,96 \%)$; el $13,25 \%$ de ellos, ocupa cargos de dirección y confianza. El $70,98 \%$ de los economistas tiene una vinculación laboral formal y el 29,02\% se consideran informales (16,47\% en mujeres y $12,55 \%$ en hombres) y el $12,64 \%$ manifiesta que su empleo actual es el mismo obtenido cuando egresaron del programa. El 36,18\% de los graduados afirman haber obtenido su primer empleo de manera inmediata y el 31,06\% tardaron en uno y seis meses en conseguir su primer trabajo. El 49,1\% (43,5\% en mujeres y 54,2\% en hombres) argumentan tener posibilidades de ascenso y promoción en el trabajo

Se revelan importantes avances en formación posgradual, así: el 33,79\% cuenta con estudios de especialización, el $21,50 \%$ con estudios de maestría y el 1,71\% con estudios doctorales. Las mujeres se inclinan en mayor número por los estudios de especialización $(38,41 \%)$ como medio de acumulación de capital humano. El 25,71\% de los economistas están vinculados a actividades de educación y formación, el 21,22\% a la administración pública, defensa y seguridad social y el 11,02\% a actividades de intermediación financiera. Así pues, un número importante de economistas son formadores de capital humano, condición esencial para garantizar mejoras en productividad y, por ende, crecimiento económico. El 41,50\% de los economistas están vinculados a instituciones o entidades públicas, el 24,51\% a empresas de mayor tamaño (con más de 201 trabajadores) y el $14,62 \%$ a microempresas con 10 o menos trabajadores. El 23,83\% de los graduados reciben ingresos laborales mensuales entre 2 y 3 smmlv, el 23,05\% entre 1 y 2 smmlv y el 18,36 entre 3 y 4 smmlv.

A partir del cálculo del Índice de Calidad de Trabajo, el empleo de los economistas no cumple con la totalidad de los estándares señalados por la OIT (1999); por lo tanto, no podría catalogarse como trabajo decente en sentido estricto; aunque cabe mencionar que las condiciones ocupacionales de los dependientes son mucho mejores que las condiciones laborales de los independientes. Por otra parte, no hay evidencia a favor de la discriminación económica (salarial, en el empleo, ocupacional y por acumulación de capital humano) que muestre diferencias sustanciales en las condiciones laborales de mujeres y hombres. Las cifras y los testimonios de los informantes no dan cuenta de 
la existencia de un trato diferencial en contra de las mujeres en la contratación, el acceso a la ocupación, los ascensos, el salario y las condiciones de empleo.

La brecha salarial de género es mínima, tal solo de $0,76 \%$ de diferencia salarial por cada año de experiencia profesional en contra de las mujeres. Por cada año de experiencia profesional de las mujeres, su salario se reduce en $0,76 \%$ en comparación la renta laboral de los hombres. La formación posgradual en maestría, incrementa el salario de las mujeres en 32,81\% en comparación con los hombres y por cada año de experiencia profesional en hombres y mujeres, el salario aumenta en 4,62\%. La edad tiene un efecto negativo en ambos sexos; por cada año adicional de edad, el salario se reduce en 1,68\% como efecto de las preferencias de los empresarios por contratar personas más jóvenes.

\section{Referencias}

(1) Acuerdo Número 018 de 1973. Por el cual se crea la Facultad de Economía de la Universidad de Nariño, Colombia. 22 de junio de 1973.

(2) Acuerdo Número 286 de 1975. Por medio del cual se concede licencia al Programa de Economía de la Universidad de Nariño, Colombia, para iniciar labores académicas en la sede Pasto. 14 de noviembre de 1975. ICFES. Bogotá, D.C., Colombia.

(3) Acuerdo Número 89 de 1976. Por medio del cual se concede licencia de funcionamiento, al Programa de Economía de la Universidad de Nariño, Colombia, resaltando que este cuenta con una estructura administrativa sólida y una calidad académica satisfactoria. 11 de junio de 1976. ICFES. Bogotá, D.C., Colombia.

(4) Acuerdo Número 111 de 1992. Por el cual se cambia el nombre de la Facultad de Economía de la Universidad de Nariño, Colombia. 28 de julio de 1992.

(5) AFADECO. (2019). Estudio de prospectiva con énfasis regional para los programas de economía de Colombia. Bogotá, D.C.: Proyectamos Colombia S.A

(6) Castel, R. (1995). La metamorfosis de la cuestión social. París, Francia. Gallimard.

(7) Castel, R. (1998). La nueva cuestión social. La metamorfosis de la cuestión social. Una crónica del salariado. Buenos Aires, Argentina: Paidós.

(8) Castel, R. y Goldstein, J. (1994). Problematization as a Mode of Reading History. Oxford, 


\section{Gran Bretaña.}

(9) Centro para la Investigación sobre la Educación Superior y el Trabajo (2004). Manual de estudios de seguimiento a egresados. U. P. Aida Midence y Ivy Lou, Trad. Bonn, Alemania: Universidad de Kassel.

(10) De La Garza, E. (2000). Tratado latinoamericano de sociología del trabajo. México, D. F., México: Fondo de Cultura Económica.

(11)Farné, S. (2003). Estudio sobre la calidad del empleo en Colombia. Estudios de economía laboral en Países Andinos, No 5. Organización Internacional del Trabajo (OIT), Lima. Recuperado el 16 de Julio de 2021, de https://www.ilo.org/public/libdoc/ilo/2003/461671.pdf

(12)Farné, S. (2013). Boletín sobre el Mercado de Trabajo y la Seguridad Social No. 14. Universidad Externado de Colombia, Bogotá, Colombia.

(13) Gálvez, S. E., Gutiérrez G. E. y Picazzo P. E. (2011). El trabajo decente: nuevo paradigma para el fortalecimiento de los derechos sociales. Vol. 73. México, D. F., México: Revista Mexicana de Sociología - Universidad Nacional Autónoma de México.

(14) García, R. K. (2020). Brecha salarial de género en Colombia. Bogotá, D.C., Colombia: DANE. Recuperado el 14 de Julio de 2021, de https://www.dane.gov.co/files/investigaciones/notas-estadisticas/nov-2020-brecha-salarialde-genero-colombia.pdf

(15) Gradua2 y Asociación Columbus. (2006). Manual de instrumentos y recomendaciones sobre el seguimiento de egresados. (n. T. Superiores, Ed.) Monterrey, México: Grupo Noriega Editores.

(16) Guba, E. y Lincoln, Y. (2002). Paradigmas en competencia en la investigación cualitativa. E. C. Sonora, Ed. 113-145.

(17)Ley 2101 de 2021 (2021, 15 de julio). Congreso de Colombia. Diario Oficial 51736.

(18) McConnell, C. y Brue, S. (1997). Economía laboral contemporánea (Cuarta ed.). (E. R. Toharia, Trad.) Madrid, España: McGraw-Hill / Interamericana de España, S.A.

(19) Mora , J. J. y Ulloa, M. P. (2011). Calidad del empleo en las principales ciudades colombianas y endogeneidad de la educación. Economía Institucional, 13(25), 163-177.

(20) Neffa, J. C. (1999). Actividad, trabajo y empleo: Algunas reflexiones sobre un tema en debate. (F. d. UNLP, Ed.) Memoria Académica, 1, 127-162. Obtenido de http://www.memoria.fahce.unlp.edu.ar/art_revistas/pr.2956/ 
(21) Offe, C. (1992). La sociedad del trabajo: problemas estructurales. Madrid, España: Alianza editorial.

(22) Organización Internacional del Trabajo (1999a). Trabajo decente. Memoria del Director General a la 87 reunión de la Conferencia Internacional del Trabajo. Ginebra, Suiza.

(23) Organización Internacional del Trabajo. Trabajo decente y la Agenda 2030 de desarrollo sostenible (9 de septiembre de 2021). Promover el crecimiento económico sostenido, inclusivo $y$ sotenible, el empleo pleno y productivo y el trabajo decente para todos. https://www.ilo.org/global/topics/dw4sd/theme-by-sdg-targets/WCMS_621378/lang-es/index.htm.

(24) Ricardo, D. (1959 [1817]). Principios de economía política y tributación. Ediciones Pirámide. México D. F, México. Fondo de Cultura Económica.

(25) Rojas, K. G. y García, R. K. (2020). Brecha salarial de género en Colombia. Bogotá, D.C.: DANE. Obtenido de: https://www.dane.gov.co/files/investigaciones/notas-estadisticas/nov2020-brecha-salarial-de-genero-colombia.pdf.

(26) Román, Y. G. \& Cervantes, A. D. (2013). El empleo precario de jóvenes asalariados en México. El caso de Toluca, Tijuana y Mérida 2005-2010. Facultad de Ciencias Económicas Universidad Militar Nueva Granada, XXI(1), 43-74.

(27) Smith, A. (1958 [1776]). Investigación sobre la naturaleza y causas de la riqueza de las naciones. México D. F., México. Fondo de Cultura Económica.

(28) Somavía, J. (2014). El trabajo decente. Una lucha por la dignidad humana (Primera ed.). Santiago de Chile, Chile: Organización Internacional del Trabajo (OIT). Obtenido de https://www.ilo.org/wcmsp5/groups/public/---americas/---ro-lima/---srosantiago/documents/publication/wcms_380833.pdf.

(29) Sotelo, A. (1997). Globalización del capital e inversión del ciclo en América Latina. (Vol. 219). (F. d. UNAM, Ed.) México D. F., México: Revista Investigación Económica.

(30) Standing, G. (2011). The precariat. The New Dangerous Class. Londres y Nueva York: Bloomsbury.

Cómo citar este artículo: Hidalgo, M. (2021). Condiciones ocupacionales de los graduados del programa de economía en la Universidad de Nariño, Colombia. Tendencias, 23(1), 277-314. https://doi.org/10.22267/rtend.222301.191 
Condiciones ocupacionales de los graduados del programa de economía en la Universidad de Nariño, Colombia. Mario Eduardo Hidalgo Villota

\section{Anexos}

\section{Anexo 1}

Resultados de las pruebas de especificación y diagnóstico del modelo (1)

\begin{tabular}{|c|c|c|c|c|c|}
\hline $\begin{array}{l}\mathrm{R}^{2}= \\
35,47 \%\end{array}$ & $\begin{array}{l}\bar{R}^{2}= \\
34,18 \%\end{array}$ & $\begin{array}{l}\mathrm{DW}= \\
1,857427\end{array}$ & $\begin{array}{l}\text { Jarque-Bera } \\
=0,995974 \\
(\text { Prob }= \\
0,607753)\end{array}$ & $\begin{array}{l}\mathrm{LM}(1)= \\
0,2902\end{array}$ & $\operatorname{LM}(2)=0,3467$ \\
\hline $\begin{array}{l}\mathrm{ARCH}(1)= \\
0,9811\end{array}$ & $\begin{array}{l}\mathrm{ARCH}(2)= \\
0,4070\end{array}$ & $\begin{array}{l}\text { WHITE } \\
\text { (cross } \\
\text { terms)= } \\
0,4360\end{array}$ & $\begin{array}{l}\text { WHITE= } \\
0,1227\end{array}$ & $\begin{array}{l}\operatorname{RESET}(1)= \\
0,3225\end{array}$ & $\begin{array}{l}\operatorname{RESET}(2)= \\
0,2389\end{array}$ \\
\hline
\end{tabular}

Nivel de significancia $=5 \%$; Skewness $=0,112770 ;$ Kurtosis $=2,793834$

Fuente: elaboración propia. 


\section{Anexo 2}

Estadísticos variables explicativas modelo (1)

\begin{tabular}{|c|c|c|c|c|c|c|c|c|c|}
\hline \multirow{2}{*}{ Estadístico } & \multicolumn{3}{|c|}{ General } & \multicolumn{3}{|c|}{ Hombres } & \multicolumn{3}{|c|}{ Mujeres } \\
\hline & Edad & Experiencia & Salario & Edad & Experiencia & Salario & Edad & Experiencia & Salario \\
\hline Mean & 41 & 14 & 3.123 .058 & 43 & 16 & 3.383 .591 & 38 & 12 & 2.827 .787 \\
\hline Median & 36 & 9 & 2.271 .315 & 40 & 14 & 3.179 .841 & 34 & 8 & 2.271 .315 \\
\hline Maximum & 71 & 40 & 7.268 .208 & 71 & 38 & 7.268.208 & 65 & 40 & 7.268 .208 \\
\hline Minimum & 23 & 1 & 908.526 & 23 & 1 & 908.526 & 23 & 1 & 908.526 \\
\hline Std. Dev. & 12,72933 & 10,95049 & 1.788 .322 & 13.29 & 11,18 & 1.905 .596 & 11,40539 & 10,24979 & 1.602 .509 \\
\hline Skewness & 0,605978 & 0,389893 & 0,896369 & 0,360509 & 0,435075 & 0,745308 & 0,883888 & 1,038560 & 1,023748 \\
\hline Kurtosis & 2,013338 & 2,149229 & 2,871063 & 1,758190 & 1,771069 & 2,465624 & 2,459127 & 2,974342 & 3,350565 \\
\hline Jarque-Bera & 26,051630 & 28,027970 & 34,459060 & 11,684420 & 12,84879 & 14,209140 & 17,087860 & 21,575430 & 21,575660 \\
\hline Probability & 0,000002 & 0,000001 & 0,000000 & 0,002902 & 0.001622 & 0,000821 & 0,000195 & 0,000021 & 0,000021 \\
\hline Sum & 10454,00 & 3590,000 & $8,00 \mathrm{E}+08$ & 5910,000 & 2183 & $4,60 \mathrm{E}+08$ & 4544,000 & 1407,0000 & $3,39 \mathrm{E}+08$ \\
\hline $\begin{array}{l}\text { Sum Sq. } \\
\text { Dev. }\end{array}$ & 41319,11 & 30577,86 & $8,16 \mathrm{E}+14$ & 23847,74 & 16882,64 & $4,90 \mathrm{E}+14$ & 15479,87 & 12501,92 & $3,06 \mathrm{E}+14$ \\
\hline Observations & 256 & 256 & 256 & 136 & 136 & 136 & 120 & 120 & 120 \\
\hline
\end{tabular}

Fuente: elaboración propia. 
Anexo 3.1

Estadísticos variables explicativas modelo (2) - Hombres

\begin{tabular}{|c|c|c|c|c|c|c|}
\hline \multirow{3}{*}{ Estadístico } & \multicolumn{6}{|c|}{ Hombres } \\
\hline & \multicolumn{3}{|c|}{ Sin formación posgradual } & \multicolumn{3}{|c|}{ Con formación posgradual } \\
\hline & Edad & Experiencia & Salario & Edad & Experiencia & Salario \\
\hline Mean & 39 & 11 & 2.485 .086 & 46 & 19 & 3.922 .695 \\
\hline Median & 34 & 7 & 2.273 .315 & 48 & 20 & 3.179 .841 \\
\hline Maximum & 66 & 37 & 7.268 .280 & 71 & 38 & 7.268 .208 \\
\hline Minimum & 23 & 1 & 908.526 & 26 & 3 & 1.362 .789 \\
\hline Std. Dev. & 11,60581 & 9,100011 & 1.663 .751 & 13,52984 & 11,06749 & 1.845 .021 \\
\hline Skewness & 0,927685 & 1,346926 & 1,705318 & 0,052116 & 0,031169 & 0,455994 \\
\hline Kurtosis & 2,713304 & 4,056041 & 5,436040 & 1,636890 & 1,551972 & 2,066022 \\
\hline Jarque-Bera & 7,489758 & 17,790640 & 5,436040 & 6,630737 & 7,429874 & 6,035119 \\
\hline Probability & 0,023638 & 0,000137 & 0,000000 & 0,036321 & 0,024235 & 0,04892 \\
\hline Sum & 1.981 .000 & 539,000 & $\begin{array}{r}1,27 \mathrm{E}+ \\
08\end{array}$ & 3929,000 & 1644,000 & $\begin{array}{r}3,33 \mathrm{E}+ \\
08\end{array}$ \\
\hline $\begin{array}{l}\text { Sum Sq. } \\
\text { Dev. }\end{array}$ & 6734,745 & 4140,51 & $\begin{array}{r}1,38 \mathrm{E} \\
+14\end{array}$ & 15376,75 & 10289,11 & $\begin{array}{r}2,86 \mathrm{E} \\
+14\end{array}$ \\
\hline Observations & 51 & 51 & 51 & 85 & 85 & 85 \\
\hline
\end{tabular}

Fuente: elaboración propia.

\section{Anexo 3.2}

Estadísticos variables explicativas modelo (2) - Mujeres

\begin{tabular}{|c|c|c|c|c|c|c|}
\hline \multirow{3}{*}{ Estadístico } & \multicolumn{6}{|c|}{ Mujeres } \\
\hline & \multicolumn{3}{|c|}{ Sin formación posgradual } & \multicolumn{3}{|c|}{ Con formación posgradual } \\
\hline & Edad & Experiencia & Salario & Edad & Experiencia & Salario \\
\hline Mean & 34 & 7 & 2.002 .465 & 40 & 15 & 3.397 .375 \\
\hline Median & 30 & 4 & 1.362 .789 & 36 & 11 & 3.179 .841 \\
\hline Maximum & 61 & 34 & 5.905 .419 & 65 & 40 & 7.268.208 \\
\hline Minimum & 23 & 1 & 908.526 & 25 & 1 & 908.526 \\
\hline Std. Dev. & 10,6419 & 8,503751 & 1.019 .642 & 11,27289 & 10,25992 & 1.687 .266 \\
\hline Skewness & 1,460163 & 1,921495 & 1,858578 & 0,655519 & 0,75936 & 0,608386 \\
\hline Kurtosis & 3,788887 & 5,481629 & 6,874018 & 2,137901 & 2,563314 & 2,650168 \\
\hline Jarque-Bera & 18,682580 & 42,726070 & 58,851570 & 7,283517 & 7,387561 & 4,741955 \\
\hline Probability & 0,000088 & 0,000000 & 0,000000 & 0,026206 & 0,024878 & 0,093389 \\
\hline Sum & 1673,000 & 355,0000 & 98120808 & 2871 & 1052 & $\begin{array}{r}2,41 \mathrm{E} \\
+08\end{array}$ \\
\hline
\end{tabular}




\begin{tabular}{lrrrrrr} 
Sum Sq. & 5436 & 3471,061 & $4,99 \mathrm{E}+13$ & 8895,465 & 7368,62 & $2,20 \mathrm{E}+$ \\
Dev. & 49 & 49 & 49 & 71 & 71 & 71 \\
Observations & 49 & & & & & \\
\hline
\end{tabular}

Fuente: elaboración propia.

\section{Anexo 4}

Resultados de las pruebas de especificación y diagnóstico modelo brecha salarial de género (2)

\begin{tabular}{|c|c|c|c|c|c|}
\hline $\begin{array}{l}\mathrm{R}^{2}= \\
30,79 \%\end{array}$ & $\begin{array}{l}\bar{R}^{2}= \\
29,68 \%\end{array}$ & $\begin{array}{l}\mathrm{DW}= \\
1,876220\end{array}$ & $\begin{array}{l}\text { Jarque-Bera } \\
=0,995974 \\
(\text { Prob }= \\
0,607753)\end{array}$ & $\begin{array}{l}\mathrm{LM}(1)= \\
0,3566\end{array}$ & $\operatorname{LM}(2)=0,1960$ \\
\hline $\begin{array}{l}\operatorname{ARCH}(1)= \\
0,6564\end{array}$ & $\begin{array}{l}\operatorname{ARCH}(2)= \\
0,7265\end{array}$ & $\begin{array}{l}\text { WHITE } \\
(\text { cross } \\
\text { terms })= \\
0,1440\end{array}$ & $\begin{array}{l}\text { WHITE= } \\
0,1383\end{array}$ & $\begin{array}{l}\operatorname{RESET}(1)= \\
0,0297\end{array}$ & $\begin{array}{l}\operatorname{RESET}(2)= \\
0,0417\end{array}$ \\
\hline
\end{tabular}

Nivel de significancia $=5 \%$; Skewness $=0,002356 ;$ Kurtosis $=2,624399$

Fuente: elaboración propia. 